\title{
Promoting Nuclear Energy: Market Pricing or Regulated Tariffs?
}

\author{
Jacques Percebois \\ University of Montpellier (UMR CNRS Art-Dev), Climate Economics Chair (Paris Dauphine University), Faculty of \\ Economics, CS 79606, 34960 Montpellier cedex2, France \\ Email: jacques.percebois@umontpellier.fr
}

\begin{abstract}
In Europe, the ability for nuclear power to compete in the energy market is undermined by two interconnected issues: a scheme of guaranteed purchase prices for renewable energy sources (wind and solar) and very low spot market prices. A feed-in tariffs system increases costs to end-users and moreover prompts decreases in the electricity price on the wholesale market. Low spot electricity prices jeopardize conventional power investments, particularly in nuclear energy. Consequently, to redress the balance between nuclear and renewable energy, it is necessary to cut subsidies for renewables and/or to help the nuclear sector through an arrangement, such as "Contract for Differences", employed in the United Kingdom. Such a mechanism may guarantee profitability of nuclear investments in the future. This paper presents, in the introduction [1], the specificity of the French electricity sector; it analyses in a second step some "perverse effects" due to the "feed-in tariffs" mechanism implemented in the European Union, particularly in France because of the system of regulated prices for the end-user [2] and presents then some suggested solutions for restoring the competitiveness of nuclear energy, which is an important goal for France [3].
\end{abstract}

Keywords: Electricity market, nuclear energy, renewable energies, energy subsidies, energy regulation, capacity market

\section{Introduction}

In Europe, the French power sector enjoys a special status for two reasons: the proportion of electricity produced by nuclear energy is very high (76\% of production in 2015 as shown in the diagram below) and the price of electricity remains largely controlled by the government at least when it comes to private households (regulated tariffs for a large part of the domestic sector). Prices for industrial customers are allowed to follow market prices. Certainly, the imposition of European directives opening up the energy sector to competition has changed many things: the incumbent no longer has a monopoly and consumers (households included) can freely choose their supplier. However, for households this is not yet the case and the incumbent's market share (EDF) remains very high; the network operators (RTE for transport and Enedis for power distribution) are subsidiaries of the incumbent, which is still mainly governmentowned (up to $85 \%$ ). This explains why, at the European Commission's request, a number of arrangements were required to reestablish balance between open competition and government intervention. French investment in nuclear energy has allowed France to benefit from a relatively low electricity price, or at least lower than the European average, a benefit French consumers do not intend to relinquish. But this advantage benefits French consumers less today since falls in electricity prices on European spot markets have been observed.

Renewable energy is a key component of the EU energy strategy and makes up about $25 \%$ of the mix of European electricity production today. In Germany the proportion is higher, at 34\%, but in France it is only $16 \%$. Nevertheless, due to the networks interconnection, German and French spot prices are largely correlated. Various schemes supporting renewable energy are operating in Europe, mainly feed-in tariffs. Europe has excess power-generation capacity and market prices have lost a great deal of meaning in a context where a proportion of the electricity injected into the transmission grid is remunerated offmarket through very advantageous feed-in tariffs. Renewable electricity sources (wind and photovoltaic) participate in spot auctions at zero marginal cost, which distorts market balance and sends a poor signal to investors, especially in a context of sluggish demand for electricity. Nuclear energy, like the renewables (sun and wind) has a particular cost structure, whereby fixed costs weigh much more heavily than 
variable costs.

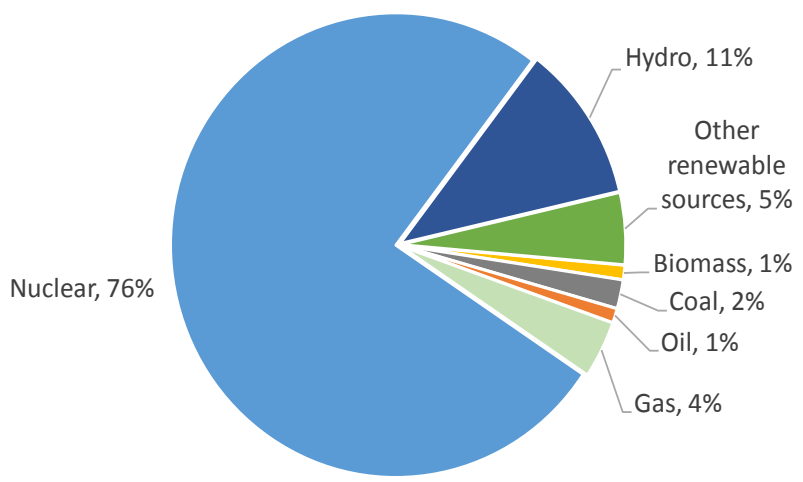

Figure 1. Structure of French Electricity Production (2015).

This means that it is necessary to cover at least variable costs at off-peak periods so as to recoup fixed costs at full and peak periods. This presupposes two conditions: (1) electricity pricing based on marginal costs, which presumes that market prices follow merit order; and (2) high power plant availability. The problem here is that merit order is slanted by a considerable volume of electricity being remunerated off-market at guaranteed purchase prices, thus stripping market prices of all meaning.

This issue has been studied in depth in recent literature mainly in Germany where the proportion of renewable energy is high, but also in Spain, Italy and France. Indeed, one of the central empirical findings in recent studies on renewable energy $(\mathrm{RE})$ is that an increase in generation from intermittent sources puts downward pressure on spot electricity market prices by displacing high fuel-cost marginal generation. Renewable installations, although they are very capital-intensive, have almost zero marginal generation cost and benefit from a priority on the spot market. More expensive conventional power plants are crowded out, and electricity prices decline.

It is worth noting that several authors have explored this topic. In Germany, Bode and Groscurth [1] find that renewable power generation lowers electricity prices. Neubarth et al. [2] show that daily spot price averages decrease by $1 € / \mathrm{MWh}$ per additional 1,000 MW wind capacity. Sensfuss et al. [3] show that in 2006 renewables reduced the average market price by $7.83 € / \mathrm{MWh}$. Weigt [4] concludes that the average market price was on average $10 € /$ MWh lower. Nicolosi and Fürsch [5] confirm that in the short run, wind power feed-in reduces prices whereas in the long run, wind power affects conventional capacity. In Denmark, Munksgaard and Morthorst [6] conclude that if there is little or no wind power $(<400 \mathrm{MW})$, prices can increase, whilst with more wind power $(>1500 \mathrm{MW})$ spot prices can be brought down. Jonsson et al. [7] show that the average spot price is considerably lower at times when greater wind power production is forecasted.

O'Mahoney and Denny [8] analyse the impact of wind energy on the Irish electricity market which is a single market with very little interconnection to the other markets. The authors estimate the historic cost savings arising from wind generation, using an hourly time series regression model for 2009 and find that the savings are significantly greater than the subsidy received for wind-generated electricity over this time period; and as a result it can be seen that the positive externalities derived from wind generated electricity outweigh the cost of subsidy.

Sáenz de Miera et al., [9] found that wind power generation in Spain would have led to a drop in the wholesale price amounting to $7.08 € / \mathrm{MWh}$ in 2005, $4.75 € / \mathrm{MWh}$ in 2006, and $12.44 € / \mathrm{MWh}$ during the first half of 2007. The study shows that this reduction is greater than the increase in the costs for the consumers arising from the renewables support scheme (the feed-in tariffs), which are charged to the final consumer. Therefore, for them, a net reduction in the retail electricity price results, which is positive from a consumer point of view. This provides an additional argument for renewables support and contradicts one of the usual arguments against renewables deployment: the excessive burden on the consumer. But it is not the case in France where the electricity prices for the end-users are largely regulated.

Benhmad and Percebois [10], using an empirical analysis based on historical data for the Germany 
electricity market between 2012 and 2015, suggest that the increasing share of wind generation and photovoltaic feed-in induces a strong decrease of electricity spot price level and has a negative impact on associated electricity systems, notably on the price paid by the domestic consumer. Phan and Roques [11] investigated empirical data on how wind production affects power prices both in Germany and in France over the years 2012-2015. Interestingly, the result shows that wind production depresses prices and increases volatility, not only domestically but also across borders. Rivard and Yatchew [12] have analyzed the impact of wind generation on the electricity prices in Ontario, a province where, unusually, electricity is bought and sold on a wholesale market while supply mix planning is conducted through a government agency. In Ontario's case, operational and market integration of renewable resources has been achieved relatively smoothly.

As mentioned in the literature, the net impacts of injection of subsidized renewable electricity are relatively ambiguous. The merit order effect tends to create surplus for consumers who buy electricity at lower prices if the price is correlated to the spot price. But they have to pay taxes when renewables are financed by feed-in tariffs. In the same time conventional producers, among them nuclear electricity producers, are receiving lower revenues and support stranded costs when some power stations are phased-out.

Another problem has to do with the fact that intermittent renewables like solar or wind power are not adequately distributed on the grid during the peak periods to recover the mark-up which would permit them to finance their fixed costs (i.e., the infra-marginal rent). This situation explains why they are subsidised off-market, with the additional cost passed on to consumers through expensive crosssubsidisation through a kind of tax which is known in France as a "Contribution to Public Service Charges for Electricity". This tax represents now about $25 \%$ of the price paid by the domestic end-user. French specificity stems from the fact that a majority of domestic and some small professional consumers used to buy electricity at a regulated selling price in 2015 (RSP). Such a price is not directly correlated to the spot market price. It is only in 2016 that regulated tariffs have disappeared for large professionals. These regulated tariffs apply only to the domestic sector, but a growing proportion of domestic consumers now tend to opt for energy at market prices. This increases consumer welfare in a context where the spot price is low. But the surplus of the conventional electricity produced (nuclear or thermal electricity produced with coal, fuel oil or gas) is falling at the same time as the spot market price.

There were about 15 electricity suppliers in the French market, but the incumbent, EDF, still supplied $85 \%$ of customers in 2015, and they were almost entirely supplied with energy at the regulated selling price. A small proportion (20\%) of non-domestic consumers, who represent only $14 \%$ of the total French customers, opted for energy offered at wholesale market prices and these consumers were supplied either by EDF, which can offer both regulated tariffs as well as energy supplied market prices, or by an alternative supplier, which can offer to supply energy only at market prices, which are generally indexed to the wholesale market.

Transnational interconnections propagate a decline in prices in one country to other neighboring countries (Germany to France particularly) as well as partially mitigating the effect on prices since part of the surplus energy is sold abroad. For example, France purchases German solar or wind electricity at certain advantageous moments, which lessens the expected German price drop: the French market plays the role of a safety valve, as suggested by Benhmad and Percebois [10]. At the same time, volatility in German prices can also spread to the French market. A country's aid policy will thus have an impact on the functioning of the markets in neighboring countries as well as on the constraints imposed on the networks of these countries.

Thus, because of their negative effects, the policies for aiding renewable energies now in force in Europe are liable to deter new investment in capital-intensive energy production, nuclear energy in particular. At the same time, it is understandable that operations with relatively high fixed costs, like nuclear power, need long-term visibility of revenues in order to ensure the profitability of investment in a sector of energy production which cannot easily adapt to volatility in market prices caused by fluctuating costs in thermal energy sources (coal- or gas-fired power plants). There are only two remaining solutions: either the market is left to function on its own, which risks provoking major 'hit and run' effects (i.e., investments occur when the market takes off and the power plants are mothballed when prices fall - but the sluggishness of supply and demand alike must be taken into account here), leaving merit order as the only index for investors; or volatility in wholesale market prices is tempered 
through corrective mechanisms guaranteeing that investors will be able to recover fixed costs at a normal rate of return on invested capital. However, regulating the prices of some energy sources while at the same time as letting the market determine prices for others is not a viable strategy because regulated energy prices effect unregulated energy prices.

A revival in nuclear energy production has become a reality throughout the world, except in the United States, where the low price of shale gas deters investments in all alternative energy sources (coalfired plants, nuclear, etc.) and in Europe, where the dysfunction in the wholesale electricity markets discourages investors. Outside Europe and North America, nuclear energy benefits either from regulated sales prices or financial support which ensures its long-term viability. This is notably the case in Asia, and especially in China. In Europe, renewable energy sources benefit from price regulation, but nuclear energy does not.

Ongoing reform of the renewable energy support mechanism in Europe, which will replace feed-in tariffs (FIT) scheme with feed-in premiums (FIP), is a step in the right direction, but only as long as an equivalent system is introduced for nuclear energy, as is the case in the UK which has introduced a scheme similar to that of "Contracts for Difference (CfD)." Fairness demands that sources of energy with similar characteristics receive identical treatment (nuclear and renewable, two energies with a high proportion of fixed costs) while sources of energy with different characteristics (thermal energies with a high proportion of variable costs and intensive carbon dioxide emissions, gas- and coal-fired plants) receive differing treatment.

In the remarks which follow, it is necessary first to analyse how current European subsidies of renewable energy sources disturb the wholesale electricity market while simultaneously weakening investment in nuclear energy. Consequently, an FIP scheme for renewable energies is perfectly compatible with a CfD scheme for nuclear energy, like the model which is now gaining favour in the UK fostering a nuclear energy revival and which France would do well to emulate.

\section{In Europe, the Nuclear Power Industry Is Undermined by Price Guarantees in the Renewable Energy Sector}

\subsection{The FIT Scheme: A Costly Mechanism}

The renewable energy sector benefits from advantageous price guarantees set by public authorities and from long-term purchase contracts (often around 15 to 20 years) with the incumbent. In general, guaranteed prices are considerably higher than the spot-market price for electricity and additional costs are borne by electricity consumers. Producers of wind or solar power do not have to worry about the sale of their product and they do not have to respond to fluctuating market prices because for them revenues have been set off-market. The rationale of the merit order entails that power stations are brought online in response to increases in marginal costs (variable costs), while the market equilibrium price will be based on the marginal costs of marginal plants. When a plant with a low variable cost itself becomes a marginal plant 'setting' the price, it can only recover variable costs; when a marginal plant with a higher level of variable costs is the marginal plant on the market, the former plant may then recover a greater proportion of fixed costs. Nevertheless, a plant with low variable costs must also have a high load factor to recover its fixed costs. Thus, a nuclear power plant is only able to recover its variable costs when it operates as a 'marginal' plant, in other words, during off-peak periods. At peak periods, prices reflect the considerably higher variable costs of a coal or gas-fired plants, which then allow a nuclear plant to recover its fixed costs. At periods of extreme demand, the price equilibrium price will be determined by combination of a marginal plant's variable costs and its fixed costs. If not, there may be a risk of 'missing money': peak plants are not able to recover their fixed costs.

Here, it is useful to look at one example. Let us assume that the power-generation fleet is composed exclusively of two kinds of plants: nuclear for the base load and diesel combustion turbine (DCT) for the peak; let $(0, \mathrm{H})$ represent peak hours and $(\mathrm{H}, \mathrm{T})$ the off-peak period ( $\mathrm{T}=8,760$ hours). Let a represent the unit fixed cost of the nuclear $\mathrm{kWh}$ and $\mathrm{b}$ the unit fixed cost of the DCT $\mathrm{kWh}$; $\mathrm{f}$ is the variable cost per operating hour of the nuclear $\mathrm{kWh}$ and $\mathrm{g}$ the variable cost per hour of operation of the DCT kWh. The cost price of the nuclear $\mathrm{kWh}$ is expressed as $\mathrm{y}=\mathrm{a}+\mathrm{fh}$, and that of the DCT $\mathrm{kWh}, \mathrm{z}=\mathrm{b}+\mathrm{gh}$, where $h$ equals the number of operating hours. We show that $y=z$ for $h=H=(a-b) /(g-f)$ (difference 
between fixed costs over difference between variable costs). The period $(0, \mathrm{H})$ corresponds here to the peak. The nuclear power station is the marginal facility during the off-peak times, and the DCT, the plant which determines the price at peak times $(0, \mathrm{H})$ because it is then the marginal facility. The optimum pricing system consists of recovering a revenue equal to $f(T-H)$ per $k W h$ during off-peak times and equal to $\mathrm{b}+\mathrm{gH}$ per $\mathrm{kWh}$ during peak times. It is clear in this case that the total revenue recovered for 1 nuclear $\mathrm{kW}$ dispatched throughout the year $(0, \mathrm{~T})$ is equal to: $\mathrm{f}(\mathrm{T}-\mathrm{H})+\mathrm{b}+\mathrm{gH}$, or, if $\mathrm{H}$ is replaced by the value indicated below, $\mathrm{a}+\mathrm{fT}$, which covers both the fixed costs and the variable costs of the nuclear power plant. If, during peak times, the price was fixed in such a way that the returns only covered the variable cost of the DCT, or $\mathrm{gH}$, the whole of the fixed costs would not be recovered. The fact of selling the nuclear $\mathrm{kWh}$ at a price permitting the recovery of $\mathrm{b}+\mathrm{gH}$ per nuclear $\mathrm{kWh}$ does not constitute unjustified income because it offers the means of covering the fixed costs of the nuclear plant. On the other hand, if, for one reason or another, the market price leads to returns higher than $\mathrm{b}+\mathrm{gH}$ during peak times, there is either a scarcity rent (if the available capacity is inadequate for satisfying all the demand) or a monopoly or oligopoly rent (if the price is manipulated and results from the "market power" of the operators present on the market). For a more detailed analysis one may refer to Percebois[13].

But a marginal cost pricing structure does not allow renewable energy producers to recover fixed costs because they are not brought online for sufficient periods of time, and rarely at the most gainful peak periods, owing to the intermittent nature of solar or wind power. Indeed, this is why payments for such energies occur off-market. It is consequently necessary to take into account the cost of the back-up tied to this intermittent supply, which requires anticipating reserve production facilities in order to take variations in available sunshine or wind into account.

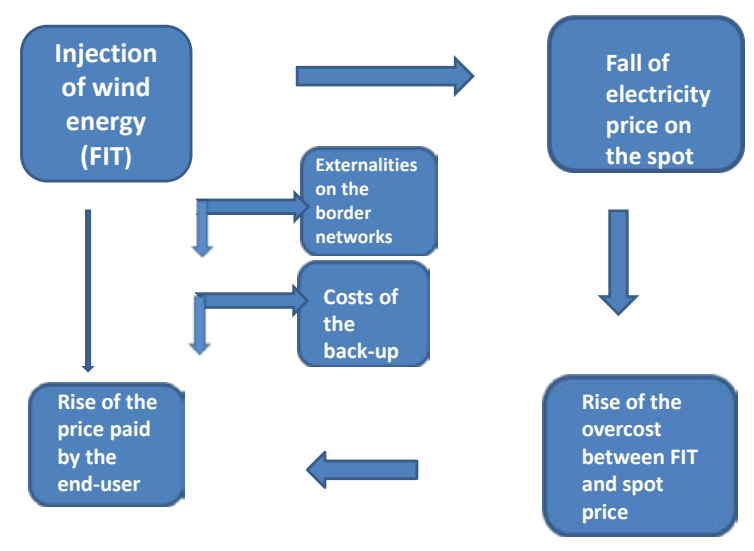

Figure 2. Perverse effects of FIT system (source J Percebois CREDEN).

Another consequence of the FIT scheme is a slanting of the merit order curve. Renewable energy sources participate in spot-market auctions at no charge because they are remunerated off-market but this has negative effects on the equilibrium price, which is consequently below the 'fair' price. Electricity prices on the spot market have shown a continuous decline in Europe and this is especially true in countries such as Germany, where the share of intermittent renewable energies is particularly high. In some cases, spot prices may even become negative; since 2009 this has often occurred in Germany. But it has also been the case in France, in particular in June 2013 and again in 2015. Since it is expensive to shut down gas- or oil-fired thermal power stations for only a few hours, it is preferable to pay operators who will take up an over-abundance of wind power (generally at off-peak periods). This is the case for Swiss operators, who have strong storage capacities for hydroelectric energy (via pumped-storage power stations) and are consequently paid to transfer the surplus energy.

Nor do these figures take into account certain network 'overflow' costs caused in the neighboring countries because of massive injections of the electricity which cannot be made use of in the producer country for lack of necessary infrastructure. This is the case, for example, in Poland, the Czech Republic and Belgium when offshore wind power produced in the Baltic Sea cannot be transferred to Bavaria 
because of inadequate high-tension lines between northern and southern Germany, so Polish, Czech and Belgian grids have to be used instead. Some of these countries have introduced mechanisms (phaseshifting transformers) to prevent influxes of the unwanted electricity or they plan to do so in future. It should be noted that the most substantial systemic costs are those related to the reserve (power plants in stand-by) rather than those of expanding grids.

Renewable energy advocates point out that, far from constituting a drawback, the slanting of the merit order curve offers advantages: these energy sources save on the fuel costs of polluting thermal power stations and thus acquire 'alternative energy value'. In other words, the availability of this intermittent electricity will cancel out the variable costs of a coal- or gas-fired plant. Replacing thermal energy by renewable electricity also avoids $\mathrm{CO}_{2}$ emissions, and this benefit should also be taken into account in economic calculations. Admittedly, the price of $\mathrm{CO}_{2}$ is very low at present (€5 - €7 per tonne) but this is not likely to continue. Intermittent electricity can also avoid peak-load investments, which permits economising not only on variable costs but also fixed ones, such as those associated with opencycle gas turbines. In addition, a decrease in the market price would represent a potential gain for endusers, or at least those with price contracts that are indexed to the spot price. This is less true for consumers with regulated selling price (RSP) contracts because in that case, the gain goes to the energy provider (not necessarily the producer). Consumers benefiting from the RSP do not benefit from it. Systemic costs also are tied to the network investments necessary for connecting renewable energy sources but also for reinforcing these networks. If the balance is negative today - renewable energies cost more than they bring in - some observers predict that the situation could be reversed in the near future owing to a drop in production costs for renewables on the one hand and a rise in the cost of fossil fuels and that of the price of $\mathrm{CO}_{2}$ on the other. But declining oil prices since mid 2014 introduce additional uncertainties about gas and coal prices.

It is also necessary to consider the fact that a decrease in the spot price will produce sunk costs for the thermal facilities in operation. If these facilities are no longer brought online, or not enough, they must be mothballed or shut down, which means that producers are obliged to organise provisions for potential losses.

The decrease in the price of electricity on the wholesale market jeopardises the competitiveness of nuclear plants currently in operation, and thus largely amortised. This situation clearly compromises the profitability of the next-generation reactors, which have no chance of competing with artificial market prices since the production cost of the MWh obtained with these reactors is considerably higher: 100 euros/MWh instead of 40 euros, as evaluated by the French Cour des Comptes [14].

The random and intermittent nature of wind power production (as well as solar, which remains marginal today) raises yet another question: that of increased volatility in electricity market prices. Benhmad and Percebois [10] used an econometric approach to demonstrate that the introduction of wind-generated electricity in Germany tended not only to lower the price on the wholesale electricity market but also tended to increase the volatility of the spot electricity price. This volatility has a cost because it requires the operators to hedge on the futures markets via financial products.

It is important, however, not to place the responsibility for all these undesirable effects and additional costs on renewable energies alone. Indeed, the main cause lies with the low demand for electricity throughout Europe. The European electricity system is faced with overcapacity because no one anticipated the stagnation of demand after the 2008 economic downturn but also because of energy efficiency policies. Renewed economic growth, demographic pressure (particularly in France, for this is not the case in Germany), new uses for electricity (especially the rapid expansion of electric vehicles) would be likely to reverse the trend and nothing excludes the possibility of new tensions between electricity supply and demand on the European market in the near future.

The effects of a massive injection of intermittent renewable energy remunerated off-market are thus complex and relatively unfavourable to consumer well-being, even if the opposite is true in certain exceptional cases. Several factors must be taken into account:

1. The merit order effect: the decrease in the spot price benefits consumers supplied through market offerings but not those paying for their electricity on the basis of regulated selling prices (RSP). It should also be borne in mind that, in some cases, renewable energy consumed by a French consumer may be financed by a German consumer, which leads to cross-border income transfers.

2. The marginal cost effect: fuel savings (or $\mathrm{CO}_{2}$ emissions avoided) via the replacement of 
thermal electricity by green electricity benefits all consumers.

3. The back-up effect: the necessity of back-up power stations in order to alleviate the problem of intermittent renewable energy supply constitutes a cost for all consumers.

4. The network effect: transmission-grid externalities tend to increase network access tariffs, which has an impact on all consumers' electricity bills. Here too, there can be cross-border transfers.

5. The sunk cost effect: the losses incurred by producers whose facilities are not cost-effective are in part borne by shareholders and in part recovered by sales prices and thus ultimately paid for by the consumer.

The decrease in spot electricity prices observed since 2008 has gradually compromised the competitiveness of thermal plants operated on gas, coal or lignite, and even that of nuclear power stations, because the spot price fell below $€ 40 /$ MWh in 2015 and again at the beginning 2016. At $€ 60$, the gas-fired plants are no longer competitive; at $€ 50$, plants operating with coal and lignite no longer recover their full cost and around $€ 40$ per $\mathrm{MWh}$, the installed nuclear plant which is partly amortised is no longer cost effective. As for the third-generation nuclear power plants, they have no chance of being competitive at current market prices.

\subsection{Towards a Feed-in Premium System?}

There is consensus in Europe about the pressing need to reform the present system of support for increasing the use of intermittent renewable energies. Several options are worth considering:

1. Decreasing the level of the feed-in tariffs (FIT) and prohibiting the injection of variable renewable energy when the spot electricity price becomes negative or falls below a certain threshold. The FIT system is expensive for the end consumer; it has often been modified and certain yo-yo effects have had unwelcome consequences on the wind and photovoltaic industries. Purchase prices have sometimes been sharply lowered, only to rise dramatically soon afterwards, thus precluding any long-term strategic vision for the industry.

2. Opting for a 'green certificate' scheme: providers required to sell a minimal quota of green electricity (via the Renewable Portfolio Standard) can either generate this electricity themselves, buy it from another provider who has a surplus, or acquire 'green certificates' from producers who are not subject to obligation but inject green electricity into the grid.

3. Promoting a feed-in with premium (FIP) system rather than the FIT: renewable electricity producers sell at the spot market price but also receive a premium (fixed or variable) depending on either the quantity of energy injected (MWh) or installed capacity (MW). This premium may be calculated ex ante or ex post. Its advantage is that providers are responsive to the market price because their main income comes from the sale of their electricity on that market. The premium is only a supplement which can in fact be regularly adjusted according to the market situation and which can be indexed to non-energy indicators (e.g., inflation, economic growth rate, etc.). In this case, the income received is variable rather than fixed, unlike the two previous systems, at least if the premium is fixed whilst the sales price on the spot market remains variable.

4. Choosing a Total Subsidy Scheme (TSS) to be distributed amongst providers: the policy-maker sets the monetary amount of the incentives to be allocated and then chooses a means of dividing up the funding (e.g., through auctions).

5. Organising auctions: public authorities launch invitations to tender for a given installed capacity in $\mathrm{kW}$ (and thus, indirectly, a quantity of $\mathrm{kWh}$ produced) and classes the bids according to merit order (increasing costs). It can then opt for auctions with a reserve price (paid at the marginal cost) or auctions with an asking price (paid as bid). The latter system has the advantage of being less expensive for the public authority and eliminating certain rents. But the 'winner's curse' described by Chari and Weber [15] is unavoidable: successful bidders only win the auction because they have tendered a lower price than their rivals and they may therefore later regret not requesting more. Admittedly, had they been more ambitious, they would have reduced the possibility of being selected, but if they had still won, profits would have accordingly been greater. Since each participant tends to anticipate this curse, they all increase the asking price and as a result, this system becomes expensive for local communities. 
6. Requiring renewable energy producers to make use of part of their electricity themselves before feeding it into the grid has the consequence that only a fraction of their production will benefit from a guaranteed income. The pricing system will then have to be revised because these consumers will remain connected to the grid and call on the incumbent when their domestic production is insufficient or faulty. A standby tariff thus has to be negotiated. Developing selfproduced renewable energy (photovoltaic particularly) affords a good opportunity to avoid network tolls which represent at least $30 \%$ of the total cost of electricity for domestic end-users.

7. Requiring energy producers to store surplus electricity (via a system of batteries, recourse to pumped-storage power stations, water electrolysis to produce hydrogen, or even the 'methanation' process associating hydrogen and $\mathrm{CO}_{2}$ to produce methane). With this 'power to gas' system, part of the hydrogen can then be injected into the natural gas network or used in vehicles. Such a solution is admittedly not profitable under current economic conditions but this might change in the near future.

At present, since 2017, France, as the most European countries, is moving towards an FIP system, as Germany has been doing since August 2014. This means that intermittent energy producers will be required to sell all or part of their energy on the spot market and will receive an income supplement in the form of a premium (most likely a fixed premium for capacity installed) intended to help them to finance the fixed costs of their facilities. France's recent law on energy changeover provides for such a scheme, at least for large-scale renewable facilities. But the inertia of the system is such that the consequences of an expensive guaranteed purchase price policy, which has disrupted the functioning of wholesale electricity markets in Europe, will continue to be felt for a long time.

\section{Restoring 'Equal Opportunity' for Nuclear Energy in Europe via a "Contract for Difference" Scheme?}

At the beginning of 2016, there were 437 nuclear reactors in operation worldwide, for an installed capacity of about 392 GWe, according to figures published by the International Energy Agency, IEA [16]. Amongst the 31 host countries identified, there were 100 reactors in the United States, 58 in France and 33 in Russia. Within the European Union, there were 131 reactors installed (in 14 of the 28 Member countries), with a total capacity of 122 GWe. Half of the nuclear energy produced in the EU comes from France.

Four new nuclear reactors are currently under construction in the EU: one EPR in Finland, one EPR in France and two VVER-400 (Russian technology) in Slovakia. Worldwide, 72 reactors, with a capacity of about 75 GWe, are under construction, including 29 in China and 10 in Russia. Many reactors have been ordered or programmed (179 according to the IEA, including 60 in China, 31 in Russia and 18 in India), and this is true for countries with significant hydrocarbon resources like Saudi Arabia and the United Arab Emirates. According to the New Policies Scenario of the International Energy Agency's World Energy Outlook 2014, the installed nuclear capacity worldwide would increase from 392 GWe in 2013 to 624 GWe in 2040; however, the share of nuclear-generated electricity, which is around $11 \%$ today, would hardly exceed $12 \%$. In absolute value, the quantity of nuclear energy produced would thus increase sharply but it would remain modest in relative value because many coal and gas-fired plants will be constructed around the world. OECD countries' share of installed nuclear capacity worldwide should decrease from $80 \%$ in 2013 to $52 \%$ in 2040, whilst that of the Asian countries would show a significant increase. China alone would represent 44\% of the new installed nuclear capacities by 2040 . Taken together, India, South Korea and Russia would represent $30 \%$ of these new capacities. The new investments to be financed by 2040 worldwide are estimated at $\$ 1500$ billion. In nearly all of these countries, the financing will take place within a planned economy, where consumers and taxpayers will pay for the investments together. Electricity prices will be largely subsidised, with no wholesale market. Nuclear energy will thus be financed to a large extent by taxes as mentioned by OECD-NEA [17].

For market-economy countries where there are wholesale electricity markets (in practice, the European Union), nuclear investments are in principle financed through the prices paid by end consumers, which reflect the wholesale market price because the regulated selling prices are scheduled to disappear. The wholesale market price represents, on average, 35 to $40 \%$ of the tax-inclusive price paid by a household consumer in France, with the remainder corresponding to the cost of regulated access tariffs (for 
transmission and distribution) and various taxes and contributions (including the CSPE). But operators who want to invest in a power plant today must take two risks into account: on the one hand, the price level of electricity on the wholesale market and, on the other, the volatility of that price on the same market. Given the uncertainties about wholesale price trends, they are likely to prefer investments with a relatively short payback period, which favours gas and coal-fired power stations. They can also hedge the risks on the financial markets but these are not sufficiently liquid to allow hedging over long time periods. In the case of an investment like nuclear energy, which has a long pay-back period, it is thus necessary to obtain sales price guarantees for future electricity produced over forty, fifty or sixty years. In the emerging economies, an approach like the BOT scheme (build, operate, transfer) might be considered: the operator constructs and operates the power plant but makes a contractual agreement with the local government or local public provider, which guarantees that the electricity produced will be purchased, over the long term, at a price ensuring the operation's cost effectiveness. In the EU, it would be possible to resort to the FIT mechanism introduced for renewable energies but in view of the criticisms it has raised, other solutions might be envisioned, such as the FIP or the CfD (Contract for Difference). The latter, which was selected in the UK for the two planned EPR reactors, seems to offer a fit compromise between the need to have confidence in the market and the necessity of guaranteeing the profitability of a highly capital-intensive investment.

The ongoing reform of the wholesale electricity market in Europe, in particular with the establishment of a capacity market, should also modify the way of taking the remuneration of fixed costs into account, and this could be a further asset for nuclear energy.

\subsection{The Case of the UK, or How to Reconcile Market Logic and the Guarantee of Profitability}

It must be indicated at the outset that the UK's nuclear power stations (the two EPR reactors programmed at the Hinkley Point $\mathrm{C}$ site) will not benefit from a subsidised feed-in tariff but from a system close to the CfD. In practice, the EDF-led consortium responsible for constructing and operating the two reactors will not be remunerated off-market, as would be the case with a feed-in tariff applied to renewable energies (wind and photovoltaic). It will sell its electricity at the market price, which means that the price signal remains strong since the investor's primary income will be earned on the wholesale market.

With its recent approval of the agreement between the consortium and the UK Government, the European Commission has confirmed that the investment in this vast project will be guaranteed. Once the EPRs come into operation, if the market price for electricity is lower than what is considered to be the project's break-even point (the reference price, which is a kind of virtual guaranteed price), the consortium will receive a top-up payment corresponding to the difference between this virtual guaranteed price and the market price for a period of 35 years. Conversely, if electricity prices soar and the project payback is greater than the price guaranteeing a given break-even point, the consortium will have to share the profits, this time for a period of 60 years: $70 \%$ for the consortium and $30 \%$ for UK authorities beyond a break-even point of $11.4 \%$; $40 \%$ for the consortium and $60 \%$ for UK authorities beyond a break-even point of $13.5 \%$. The reversibility of this agreement is essential. The income supplement will only be granted ex post and according with a theoretical break-even point for the capital invested. It may be that the future winner will be the UK rather than the consortium. The obvious question is who will finance the income supplement: the UK energy consumers (whether this is nuclear or not) or the taxpayers? As things stand, it will probably be the taxpayers.

Such a system is reversible: if the market price is too high relative to a compensation rate set ex ante, the electricity seller has to pay part of the revenues to UK authorities so as not to exceed the agreedupon rate of return on capital (the reference price guarantees the targeted break-even point for the capital invested).

The first difference between the CfD and the FIT is that in the case of the former, the operator's primary income comes from the wholesale market price, whilst in the latter, this price is of no concern to the operator. The second difference is that with the CfD, the income supplement is calculated according to an 'objective' rate of return on capital invested and can be either positive or negative (reversibility principle). With the FIT, the income is based on a regulated price set in absolute value from the outset, irrespective of any concern for profitability (if the tariff is too advantageous, the return 
on capital can be excessive, leading to a windfall profit effect).

The difference between the CfD and the FIP (where a premium is paid ex post in function of installed capacity) is that the income received with the CfD is adjusted to keep the guaranteed rate of return on capital constant and that this income should remain relatively stable over time in constant currency, whilst the income received with the FIP is variable because it is obtained by adding together a variable sales price (the wholesale market price of the MWh) and a fixed premium generally calculated per installed MW. As a result, the return on capital invested varies as well.

What message has the European Commission sent in approving the financial package proposed for Hinkley Point C? It has recognised that an investment in nuclear energy cannot be undertaken today without Government support and prospects of long-term profitability. The nuclear industry obeys a 'long term' logic: new reactors have a lifespan of sixty years and this means that the return on investment is also a long-term process. At a time when nuclear energy is picking up again throughout the world, it is important to give it a new boost in Europe. It is a cutting-edge technology, contributing in association with renewable energy sources to slowing global warming.

On the other hand, this plea should not be seen as an argument against sources of renewable energy. The European Commission has never suggested that assistance to these renewable energy sources should be suspended. Rather, it looks forward to producers selling renewable energy at market prices, with a compensatory premium if the market-level tariffs are too low. This arrangement resembles one introduced in the UK for nuclear power, albeit with certain differences. It would be based on the FIP scheme, whereby producers sell renewable electricity at the spot price and benefit ex post from a premium per MW installed (or possibly a premium per MWh fed in). The income received is thus variable because it is the sum of a fixed premium and a variable market price.

\subsection{The Capacity Market, an Asset for the Nuclear Industry?}

One of the criticisms directed at the wholesale market as it operates today within the European Union is that it pays for energy (MWh injected) and not directly for power (MW). Admittedly, the capital is indirectly remunerated through the price per MWh only when this exceeds variable costs, but this is not the case for a facility which is not feeding into the grid (even if it remained useful as a back-up in case of a possible system failure). This is inefficient in collective terms. If the wholesale market functioned optimally, fixed costs would be covered by the infra-marginal rent for the baseload plants and by the scarcity rent for the peaking plants, so that the income from MWh sales would suffice to ensure profitability for the entire power-generation park. However, the wholesale market does not function optimally, on the one hand because the injection of electricity purchased off market reduces the inframarginal rent and, on the other, because the peak price does not always permit the recovery of peaking plants' fixed costs (cf. the missing money problem discussed above). This arrangement does not encourage investments that would manage consumption peaks more effectively.

With the capacity market, which is scheduled to be introduced in France as in several European countries as explained by Buchsteeg and al. [18], providers should have the necessary capacity to be able to meet customer demand. This will be achieved either by having a portfolio of customers subject to peak-day load reduction or by investing in peak capacity, if not also by storing electricity (hydroelectric dams, pumped-storage systems). This 'capacity scheme' can be complemented by a capacity market for exchanging capacity (MW) by means of certificates between mandatory participants. Several solutions are investigated:

1. The "strategic reserve" mechanism: operators of the transmission grid auction off capacity which can be used in case of possible system failure. Remuneration is set by tender and this reserve capacity is not available on the market but constitutes a kind of generator of last resort which can only be used by grid operators.

2. The capacity payment mechanism: the regulator determines a fixed price which rewards new installed capacity becoming available, thus encouraging producers to invest. This is in fact a feedin premium system where the premium is set ex ante per installed MW, but which is limited to peak capacity alone.

3. The capacity market: this time the price allocated to the power is a market price.

With regard to these capacity mechanisms that are being set up, whether through a reserve as in Germany or though markets in many other countries including France, the European Commission 
mandates that the resulting capacity payments are not used as a hidden subsidy for the benefit of operators of high-carbon fuelled plants (coal or lignite).

Remunerating installed capacity independently of its load factor encourages operators to invest in peak capacities. Operators will receive additional payment if they can guarantee that their power stations will be able to generate electricity at given moments during peak periods. Some countries, like Germany, are hostile to a capacity market which would remunerate capacity independently of energy because they fear new 'gold-plating' for regulated electricity companies, which would be encouraged to over-invest in fossil-fired plants. It should be pointed out that it is also necessary - and rightly so - to remunerate consumers who accept to reduce their loads during peak periods, which raises problems of measuring reduction. Capacity mechanisms, with the exception of strategic reserves, must be open to participation by capacity providers located in another Member State, as soon as an interconnection exists.. It should be added that, for the European Commission, the remuneration of capacities must be determined on the basis of market mechanisms and not directly by the public authorities. Should the capacity mechanism be open to any type of capacity, such as nuclear and renewable energies? For nuclear it is acceptable if the market price is not sufficient to recover fixed costs. However, it is questionable whether renewable energies should benefit from the capacity mechanism when they already receive support in the form of supplementary remuneration. Would there not be a "double dividend" for renewable energy?

In principle, this mechanism has little impact on nuclear facilities because they are baseload plants. The cost price of nuclear power MWh is calculated over an operating period which is much longer than that of a classic thermal power station, in a context where prices observed on the wholesale market are quite volatile over the short term. The capacity market should help to smooth out consumption peaks and thus price peaks, which would limit the remuneration obtained by the baseload suppliers during peak periods. Investors in the nuclear industry are therefore wary of facing sunk costs if market prices are insufficient to cover an investment which is only profitable over the long term and they prefer to make investments with shorter payback periods and lower risks. Since hedging instruments do not provide a cover over the very long term, investors demand institutional guarantees. And the contract for difference scheme is one form of guarantee.

It is conceivable that nuclear facilities could be granted premiums which would remunerate installed capacity in the event that the price observed on the wholesale electricity market would not permit a return on investment. This would be a kind of FIP scheme but would only be applied below a bottom price for the electricity sold on the spot market and, in this case, would amount to guaranteeing a minimum return rate for nuclear energy. The system is thus close to the "Contract for Difference" scheme but unlike the latter, it does not provide for deducting the infra-marginal rent beyond a certain ceiling, in other words, when the wholesale market price becomes very high. There would be a bottom price, but no ceiling price.

It is also conceivable that the amount of the premium paid could be reviewed periodically through a mechanism known as the 'expenses and revenues clawback account', which is used for network investments (transmission and distribution of the electricity). This means guaranteeing an objective rate of return on the capital invested and deducting the infra-marginal rent when this rate is exceeded, which bears a resemblance to the CfD system in the strict sense. The incentives for investors would not be as strong as those of the UK scheme because beyond the objective rate of return (ceiling price), all profits are recovered by public authorities (and/or redistributed to consumers), whilst with the British scheme the profits are shared between the producer and the Government.

\section{Conclusion}

The manner in which today's spot electricity market has been structured does not send the right signals to investors, not only because it is a short-term market but also because the electricity sold at a regulated price set off market distorts prices overall. What will happen when the share of renewable energies with very low marginal costs in the power mix becomes very high, if at the same time guaranteed purchase prices and income supplements are ended? Most of the time wholesale market prices will be very low and producers will be unable to recover their fixed costs. Ultimately, with $100 \%$ renewables at zero marginal cost, the market price will no longer make sense. There is then a risk of 
power plants shutting down (and consequent blackouts), as plants still in operation cannot recover their investment. Certainly the existence of a capacity mechanism is a partial but temporary response. Practically there are two possible solutions to this problem: either the market is allowed to operate freely and so to send clear signs to all investors including those in renewable energies (this is likely to give rise to large fluctuations in investment cycles related to the sharp volatility of the spot prices), or a minimum of regulation is introduced in order to limit costly surges of under- and over-capacity. But in the latter case, all the energy sources must receive equal treatment but the nuclear industry must also receive guarantees that it will also recover its fixed costs over the long term. In essence, that means that there is a need for an energy policy with a long-term vision of electricity supply and demand that has a global perspective on the industry. This would not prevent the market from sending signs that would enable planners to correct inevitable errors.

\section{References}

1. S. Bode and H.M. Groscurth, "The Effect of the German Renewable Energy Act (EEG) on the electricity price", HWWA Discussion Paper (348), 25 p, 2006.

2. J. Neubarth, O. Woll, C. Weber, and M. Gerecht, "Influence of Wind Electricity Generation on Spot Prices", Energiewirtschaftliche (56), pp. 42-45, 2006.

3. F. Sensfuss, M. Ragwitz, and M. Genoese, "The merit-order effect: A detailed analysis of the price effect of renewable electricity generation on spot market prices in Germany" Energy Policy, (36), pp. 3086-3094, 2008.

4. H. Weigt "Germany's Wind Energy: the potential for fossil capacity replacement and cost saving", Applied Energy, 86 , pp. $1857-1863,2008$

5. M. Nicolosi,and M. Fürsch, "The impact of an increasing share of RES-E on the conventional power market - The example of Germany", Zeitschrift für Energiewirtschaft (33), pp. 246-254, 2009.

6. J. Munksgaard,and P.E. Morthorst, "Wind power in the Danish liberalised power market; Policy measures, price impact and investor incentives", Energy Policy (36), pp. 3940-3947, 2008.

7. T. Jonsson, P. Pinson, and H. Madsen, "On the market impact of wind energy forecasts", Energy Economics, 32(2), pp. 313-320, 2010.

8. A. O'Mahoney and E. Denny, "The merit order effect of wind generation in the Irish electricity market", Proceedings of the 30th USAEE/IAEE,MPRA, Washington D.C., October, 14 p, 2011.

9. G. Saenz de Miera, D.G. Rio, and I. Vizcaino, "Analysing the impact of renewable electricity support scheme on power prices: the case of wind electricity in Spain", Energy Policy, vol. 36(9), pp. 3345-3359, 2008.

10. F. Benhmad, and J. Percebois,"Wind power feed-in impact on electricity prices in Germany 2009-2013", The European Journal of Comparative Economics, Vol. 13, no. 1, pp. 81-96, 2016.

11. S. Phan and F. Roques, "Is the depressive effect on renewable on power prices contagious? A cross border econometric analysis", CEEM Working Paper 2015-16, European Electricity Market Chair, Paris Dauphine University, 25 p, 2015.

12. B. Rivard and A. Yatchew, "Integration of Renewables into the Ontario Electricity System", The Energy Journal, 37, pp. 221-242, 2016.

13. J. Percebois, "The French Electricity Market: Competition, Nuclear Rent and Price Regulation" chapter 3 in F. Sioshansi (Editor) "Evolution of Global Electricity Markets", Elsevier, June, 2013.

14. Cour des Comptes "Le coût de production de l'électricité nucléaire" (communication à la Commission d'Enquête de l'Assemblée Nationale,Paris, 26 May, 2014.

15. V. Chari and R.J. Weber "How the US Treasury should auction its Debt?", Federal Bank of Minneapolis Quarterly Review, Fall, vol 16, no.4, pp. 3-12, 1992.

16. I.E.A. (International Energy Agency) "World Energy Outlook", Paris, 2014.

17. OECD-NEA "Nuclear Energy and Renewables; System Effects in Low-carbon Electricity", Paris, 2012.

18. M. Buchsteeg, S. Spiecker and C. Weber, Impact of Coordinated Capacity Mechanisms on the European Power Markets, House of Energy Markets and Finance, HEMF Working Paper no. 01, January, 37 p, 2017. 